\title{
A review of secondary pentobarbital poisoning in scavenging wildlife, companion animals and captive carnivores
}

\author{
Kathleen Wells ${ }^{1}$, Andrew Butterworth ${ }^{1}$ PhD, Ngaio Richards',3 PhD
}

\begin{abstract}
Sodium pentobarbital is a veterinary drug commonly employed to euthanize different animal species humanely. Cases of secondary pentobarbital poisoning also have been documented in scavenging wildlife, companion animals and captive carnivores. Since the extent of such poisonings remains mostly unknown, a review was undertaken to consolidate cases published, recorded, only locally reported or shared anecdotally. A questionnaire was distributed to veterinary surgery and wildlife rehabilitation centers, and zoos. An estimated 125 cases affecting 432 animals across the US, Canada, the UK, South Africa, New Zealand, Australia, Germany and France were collated, with $76.8 \%$ obtained outside the published literature. Our findings support that 1) pentobarbital poisoning affects a range of wild species (e.g., griffon vultures, canids) and companion animals (especially dogs and captive carnivores), and 2) although a known source of toxicosis, pentobarbital-related poisonings continue to the present day. Carcass disposal methods were considered in regards to associated incidents of secondary poisoning. Wild scavengers and companion animals were mainly affected after feeding on livestock carcasses that were insufficiently buried or left uncovered. Captive carnivores were accidentally poisoned after being fed pentobarbital-euthanized animals. Euthanized carcasses of stranded whales, provision of euthanized carcasses to dogs at hunt kennels, sourcing of meat from fisheries and laboratories, and use of barbiturates in baits to deliberately harm wildlife also emerged as noteworthy sources of risk or exposure. The ongoing presence of pentobarbital residues in pet food as a threat to companion animals also was incidentally considered. Additional recommendations for follow-up research, to increase awareness of this issue and prevent exposure, were suggested.
\end{abstract}

KEYWORDS: veterinary forensic sciences, wildlife, pentobarbital, secondary poisoning, carcass, euthanasia, pet poisoning

The global occurrence of accidental and intentional animal poisonings and the ensuing ecological ramifications are welldocumented (Guitart et al. 2010). Pesticides, nonsteroidal antiinflammatory drugs (NSAIDs), heavy metals (e.g., lead), and anticoagulant rodenticides are either frequently reported causes of such poisoning or have been associated with conspicuous incidents of mortality (Barnett et al. 2005, Brakes and Smith 2005, Russell and Franson 2014, Zorrilla et al. 2014).

Cases of secondary poisoning due to the euthanasia drug sodium pentobarbital (aka pentobarbitone) have been documented in both wild and companion animals and sporadically in captive carnivores (e.g., Edgson and Payne 1967, Marton and Mallock 1978, Krueger and Krueger 2002, Leary et al. 2013, Gonzales and Clifford 2015). Compared to the toxicants mentioned above, pentobarbital has been much less implicated in incidents of debilitation and mortality.

Pentobarbital is a barbiturate classified as a controlled Schedule II substance in the US and as a Schedule III substance in the UK. Barbiturates cause a swift depression of the central nervous system, starting in the cerebral cortex. The delivery of an overdose results in a loss of consciousness which progresses first to deep anesthesia then to apnea, due to the depression of the respiratory center, and finally culminates in cardiac arrest (AVMA 2013). After death, the barbiturate solution, often formulated with an anticonvulsant (e.g., phenytoin), concentrates in highly vascularized organs, such as the liver and spleen (Thomas 1999), some of which may be preferentially ingested by scavenging species (e.g., König 1983, Hertel 1994, Elliott et al. 2006).

Numerous wild animals, particularly species that feed communally, may be impacted by a single contaminated carcass. For example, in an often-cited case which occurred in 1988, 29 bald eagles (Haliaeetus leucocephalus) were poisoned in British Columbia, Canada after feeding on the carcass of a cow that had been euthanized then intentionally left uncovered on a farmer's property (Langelier 1993). Unaware that the dead cow could harm the eagles, and therefore without malicious intent, the farmer simply intended to make them available to the birds as a food resource. Similarly, captive carnivores, including tigers (Panthera tigris), lions (Panthera leo), and cheetahs (Acinonyx jubatus), have unintentionally been poisoned at zoos across several continents after being fed the carcasses of animals euthanized using pentobarbital (AZA n.d., Verster et al. 1990, Williams et al. 2011). Companion animals (dogs and cats) face two main exposure scenarios: 1) by scavenging on the carcasses of euthanized animals while free-roaming outside (e.g., Kaiser et al. 2010), or 2) by consuming tainted canned pet food containing by-products of animals euthanized with pentobarbital (e.g., Edgson and Payne 1967, FDA 2017) believed to have been made safer by the rendering process (AVMA 2013). Indeed pet food recalls continue

\footnotetext{
1 Division of Food Animal Science, University of Bristol Langford, Langford, BS40 5DU, UK

2 Working Dogs for Conservation, PO Box 280, Bozeman, MT 59771, USA

3 William R. Maples Center for Forensic Medicine, Department of Pathology, Immunology and Laboratory Medicine, University of Florida, 4800 SW 35th Drive, Gainesville, FL 32608

Corresponding author: Kathleen Wells, kw16522.2016@my.bristol.ac.uk, (+44)7534343663

Received 31 Jan 2018; in revised form 24 Jan 2019; accepted 24 April 2019.
} 
to be sought or enforced following the detection of pentobarbital residues in a variety of products (e.g., Neal 2018, Entis 2019).

This cross-section of cases and the decades-long timespan duly reflects that poisoning of scavenging wildlife, companion animals and captive carnivores following exposure to pentobarbital residues is not in and of itself a novel finding. Yet equally such cases are still being reported across all three categories of animals. This, paired with the fact that the current array of secondary pentobarbital poisoning cases reported in the literature likely does not fully characterize the extent of the issue, provided the impetus for this work, which served primarily as an information-gathering exercise to expand upon current knowledge and generate further awareness of this issue, focusing upon the range of poisoned species, current carcass disposal and provision practices, and level of cognizance of the problem among animal practitioners and caregivers. This study was performed through a review of reported or published cases, questionnaire analysis, and strategic personal communications. Incidences of exposure in tainted pet food were examined, and any novel or unexpected exposure contexts or euthanized animal carcass management practices, in addition to those currently favored, also were noted.

\section{Materials and Methods}

This review comprised two main components: 1) consolidation and collation of secondary pentobarbital poisoning records from existing publications, with cross-verification of wildlife poisoning databases for any cases not present in the literature, and 2) questionnaire sampling of veterinary surgical and wildlife rehabilitation centers, and zoos. The information gathered by the above means was further augmented through informal (and targeted) personal communications, wherein relevant experts and members of conservation organizations (e.g., BirdLife) were approached via email (by primary author K. Wells) and invited to provide in-house perspectives on, or records of, pentobarbital-related poisoning, as available. In the case of poisoning incidents following consumption of tainted pet food, the review also extended to consumer safety bulletins for pet food recalls (e.g., DogFoodAdvisor, dogfoodadvisor.com/dog-foodrecall-alerts) and perusal of newspaper articles.

\section{Identification and research of published or reported poisoning cases}

Records of secondary pentobarbital poisoning were collated from published journal articles. Databases of the Wildlife Case Investigation Scheme (WIIS: UK), National Wildlife Health Center (NWHC: US) and Veterinary Poisons Information Service (VPIS: UK) also were consulted. Cases were recorded and analyzed in a Microsoft Excel spreadsheet under the following headings: date and location of the case, species or breed of both the poisoned and source animal, number affected and killed, source animal disposal methods, how the case was confirmed, as well as any additional salient information.

\section{Questionnaire sampling}

Review and ethical approval for the questionnaire (Appendix) was granted by the Faculty of Health Science Research Ethics Committee (HSSREC) and the Animal Welfare and Ethical
Review Body (AWERB) of the University of Bristol Veterinary School. The questionnaire was sent to 291 veterinary surgical centers, 195 wildlife rehabilitation centers, and 79 zoos in the UK, the US, Canada, Australia and New Zealand $(n=565)$. The selection of these organizations was random. Every third organization, as listed, was contacted from Vets Directory UK (vetsdirectory.co.uk), The Wildlife Rehabilitation Information Directory (wildliferehabinfo.org), USA Zoos (usa-zoos.com) and Bizland (zoos.bizland.com/alphabetical.htm).

The questionnaire was made up of three general sections: 1) euthanasia methods, 2) disposal techniques, and 3) provision of food. Questions were posed with both multiple selectable options and as open requests for information, to be provided in 'longhand,' regarding safety protocols and euthanasia practices. Respondents were allowed to disclose the occurrence of pentobarbital poisoning within their facility. The collected data were stored anonymously in a Microsoft Excel spreadsheet.

Seven underlying, inter-related questions steered our efforts for the review undertaken:

1) Which types of animals are most susceptible to exposure and poisoning?

2) What level of awareness exists among veterinary practitioners and animal caregivers on this issue?

3) How are the carcasses of various types of euthanized animals disposed of, and which of these are associated with secondary poisoning incidents?

4) Where do animal care and zoo facilities source carcasses and animal parts for provisioning captive wildlife and other animals?

5) How is the safety of those carcasses and parts (relative to pentobarbital residues) assured?

6) What can be the outcome of not enacting safety protocols and verification?

7) What monitoring measures are currently in place for detecting secondary pentobarbital poisoning cases, and which factors influence reporting and detection rates?

\section{Results and Discussion}

An estimated 125 cases, spanning 1967 through 2017 and cumulatively affecting 432 animals, were collated and analyzed for this review. The number of cases is a conservative estimate because in a few poisoning instances (e.g., Russell and Franson 2014) insufficient information was provided to determine a specific number of cases; the overall number of animals affected was then counted as a single case $(1$ or $>1)$. Tables 1 and 2 summarize cases by category of animal (companion, captive carnivore, scavenging wildlife) in ascending chronological order, as obtained from the published literature $(n=29)$ and via questionnaires, database review and personal communications $(n=96)$, respectively.

Of the 565 facilities contacted, 26 responded by completing the questionnaire: 10 veterinarians (3.4\% of 291 surgical centers), 11 wildlife rehabilitators (5.6\% of 195$)$ and five zoo staff $(6.3 \%$ of 79). Across all types of inquiries and forms of information gathering, cases were documented from the UK, the US, Canada, South Africa, New Zealand, Australia, Germany and France. Data from the last two locations were exclusively from personal communications, as documented in Tables 1 and 2. We further 
note that cases were found to have been reported across North America, in nine US states: Alaska, Washington, California, Nevada, Colorado, Florida, South Carolina, Virginia and Maine; and four Canadian geographical areas: Yukon, British Columbia, Alberta and Ontario.

Having finalized the manuscript and supporting tables, the authors realized that a case from 2017 involving the secondary pentobarbital poisoning of seven turkey vultures in California (cdfgnews.wordpress.com/2017/11/07/turkey-vultures-poisonedby-euthanasia-drugs) was inadvertently omitted from the dataset.
Similarly, anecdotal information from a California-based veterinarian regarding a case from 2007, in which two moribund dogs were admitted, came to light after the manuscript submission. Briefly, the two dogs had excavated and scrounged the bones of a horse that had been euthanized some ten years prior. Stomach contents were tested twice at the Michigan State University laboratory and tested positive for barbiturate residues both times. Both cases underscore the core points of this review: secondary pentobarbital poisoning is ongoing and must be more directly addressed.

TABLE 1-Cases of secondary pentobarbital poisoning in companion, captive, wild or free-roaming animals as reported in published literature (1967-2016)

\begin{tabular}{|c|c|c|c|c|c|c|c|}
\hline Country & Poisoning location & $\begin{array}{l}\text { Animal } \\
\text { category }\end{array}$ & $\begin{array}{l}\text { Cases } \\
\text { reported }\end{array}$ & Species & $\begin{array}{l}\text { Animals } \\
\text { affected }\end{array}$ & Year(s) & Reference \\
\hline UK & Berkshire & $\mathrm{Ca}$ & 2 & $\begin{array}{l}\text { cat (1) } \\
\text { dog - Irish terrier (5) }\end{array}$ & 6 & 1967 & Edgson and Payne (1967) \\
\hline$A U$ & Victoria & $\mathrm{Ca}$ & 2 & $\begin{array}{l}\text { dog - German shepherd (2) } \\
\text { dog - terrier, Border collie (2) }\end{array}$ & 4 & 1971 & Williamson (1971) \\
\hline NZ & NR & $\mathrm{Ca}$ & 3 & $\begin{array}{l}\text { dog - greyhound (4) } \\
\text { dog - greyhound (8) } \\
\text { dog - Springer spaniel (1) }\end{array}$ & 13 & $1976-77$ & Reid (1978) \\
\hline UK & Somerset & $\mathrm{Ca}^{\mathrm{a}}$ & 2 & $\begin{array}{l}\text { dog - foxhound ( } 70) \\
\text { dog - fox terrier ( } 2 \text { ) }\end{array}$ & 72 & 1977 & Polley and Weaver (1977) \\
\hline UK & NR & $\mathrm{Ca}$ & 1 & dog-unspecified breed & 1 & 1979 & Anderson et al. (1979) \\
\hline UK & NR & $\mathrm{Ca}$ & 1 & dog-spaniel & 1 & 1980 & Humphreys et al. (1980) \\
\hline US & Massachusetts & $\mathrm{Ca}$ & 1 & dog - American bulldog & 1 & 1980 & de Laforcade et al. (2001) \\
\hline US & NR & $\mathrm{Ca}$ & 1 & dog - Samoyed & 1 & 1986 & \\
\hline US & Colorado & $\mathrm{Ca}$ & 1 & dog - border collie, blue heeler & 2 & 2009 & Campbell et al. (2009) \\
\hline $\mathrm{DE}$ & Hannover & $\mathrm{Ca}$ & 1 & dog-dachshund, Münsterländer & 2 & 2009 & Brauer et al. (2009) \\
\hline US & NR & $\mathrm{Ca}$ & 1 & $\begin{array}{l}\text { dog - Labrador retriever, } \\
\text { Australian shepherd }\end{array}$ & 2 & 2010 & Kaiser et al. (2010) \\
\hline US & New York & $\mathrm{Ca}$ & 1 & dog - Australian shepherd & 1 & 2011 & Bischoff et al. (2011) \\
\hline US & Florida & Cc & 1 & cougar (Felis concolor) & 3 & 1987 & Martin and Mallock (1987) \\
\hline SA & Pretoria & Cc & 1 & lion (Panthera leo) & 1 & 1988 & Verster (1990) \\
\hline DE & Heidelberg & Cc & 1 & $\begin{array}{l}\text { Sumatran tiger } \\
\quad(P . \text { tigris sumatrae })\end{array}$ & 3 & 2007 & Jurczynski and Zittlau (2007) \\
\hline SA & Pretoria & Cc & 1 & tiger (P. tigris) & 3 & 2011 & Williams et al. (2011) \\
\hline US & Alaska & W & 2 & $\begin{array}{l}\text { bald eagle } \\
\quad \text { (Haliaeetus leucocephalus) }(4,5)\end{array}$ & 9 & 1987 & Thomas (1999) \\
\hline CA & British Columbia & W & 1 & bald eagle & 29 & 1988 & Langelier (1993) \\
\hline US & Alaska & W & 2 & eagle - unspecified & 2 & 2008 & Jozwiak (2009) \\
\hline US & NR & W & 1 or $>1 \mathrm{~b}$ & $\begin{array}{l}\text { bald eagle, } \\
\text { golden eagle (Aquila chrysaetos) }\end{array}$ & 36 & 1982-2013 & Russell and Franson (2014) \\
\hline US & NR & W & 1 & bald eagle & 8 & 2016 & Viner et al. (2016) \\
\hline
\end{tabular}

UK, United Kingdom; AU, Australia; NZ, New Zealand; US, United States; DE, Germany; SA, South Africa; CA, Canada; Ca, companion animal;

Cc, captive carnivore; W, scavenging wildlife; NR, not reported or insufficient information provided to make a determination.

a. This incident occurred in captivity, while the dogs were housed at a hunt kennel.

b. Insufficient information was provided in Russell and Franson (2014) to determine a specific number of cases in association with the total number of animals $(\boldsymbol{n}=36)$ affected overall. This overall total was therefore counted as a single case, but reported as 1 or $>1$, indicating it is a conservative estimate. 
TABLE 2-Cases of wild, companion and captive animal secondary pentobarbital poisonings as obtained from database research, personal communications, and questionnaire responses

\begin{tabular}{|c|c|c|c|c|c|c|}
\hline Country & $\begin{array}{l}\text { Poisoning } \\
\text { location }\end{array}$ & $\begin{array}{l}\text { Animal } \\
\text { category }\end{array}$ & Species & $\begin{array}{l}\text { Animals } \\
\text { affected }\end{array}$ & Year & Source \\
\hline UK & NR & $\mathrm{Ca}$ & cat & 1 & 1993 & database research \\
\hline UK & NR & $\mathrm{Ca}$ & dog & 1 & 1993 & database research \\
\hline UK & NR & $\mathrm{Ca}$ & dog & 1 & 1996 & database research \\
\hline UK & NR & $\mathrm{Ca}$ & $\operatorname{dog}$ & 1 & 1997 & database research \\
\hline UK & East Sussex & $\mathrm{Ca}$ & $\operatorname{dog}$ & 4 & 1998 & database research \\
\hline UK & NR & $\mathrm{Ca}$ & dog - cocker spaniel & 1 & 1998 & database research \\
\hline UK & NR & $\mathrm{Ca}$ & dog-border collie & 1 & 1999 & database research \\
\hline UK & NR & $\mathrm{Ca}$ & dog-border collie & 1 & 1999 & database research \\
\hline UK & NR & $\mathrm{Ca}$ & $\operatorname{dog}$ & 1 & 2000 & database research \\
\hline UK & NR & $\mathrm{Ca}$ & dog - Jack Russell terrier & 1 & 2001 & database research \\
\hline UK & NR & $\mathrm{Ca}$ & dog - border collie & 1 & 2002 & database research \\
\hline UK & NR & $\mathrm{Ca}$ & dog - German shepherd & 1 & 2003 & database research \\
\hline UK & NR & $\mathrm{Ca}$ & $\operatorname{dog}$ & 1 & 2006 & database research \\
\hline UK & NR & $\mathrm{Ca}$ & dog - Labrador retriever & 1 & 2006 & database research \\
\hline UK & NR & $\mathrm{Ca}$ & dog - border collie & 1 & 2008 & database research \\
\hline UK & NR & $\mathrm{Ca}$ & dog - Jack Russell terrier & 1 & 2008 & database research \\
\hline UK & NR & $\mathrm{Ca}$ & dog-pointer & 1 & 2008 & database research \\
\hline UK & NR & $\mathrm{Ca}$ & dog & 1 & 2009 & database research \\
\hline UK & NR & $\mathrm{Ca}$ & $\operatorname{dog}$ & 1 & 2010 & database research \\
\hline UK & NR & $\mathrm{Ca}$ & dog - German shepherd & 1 & 2010 & database research \\
\hline UK & NR & $\mathrm{Ca}$ & dog - German shepherd & 1 & 2010 & database research \\
\hline UK & NR & $\mathrm{Ca}$ & dog - Labrador retriever & 1 & 2010 & database research \\
\hline UK & NR & $\mathrm{Ca}$ & dog - spaniel & 1 & 2010 & database research \\
\hline NR & NR & $\mathrm{Ca}$ & dog & 5 & 2011 & database research \\
\hline UK & NR & $\mathrm{Ca}$ & dog & 1 & 2011 & database research \\
\hline UK & NR & $\mathrm{Ca}$ & dog & 1 & 2011 & database research \\
\hline UK & NR & $\mathrm{Ca}$ & dog & 1 & 2011 & database research \\
\hline UK & NR & $\mathrm{Ca}$ & $\operatorname{dog}$ & 1 & 2011 & database research \\
\hline UK & NR & $\mathrm{Ca}$ & dog & 1 & 2011 & database research \\
\hline UK & NR & $\mathrm{Ca}$ & dog - Bernese mountain & 1 & 2011 & database research \\
\hline UK & NR & $\mathrm{Ca}$ & dog - border collie & 1 & 2011 & database research \\
\hline UK & NR & $\mathrm{Ca}$ & dog-border collie & 1 & 2011 & database research \\
\hline UK & NR & $\mathrm{Ca}$ & dog - Jack Russell terrier & 1 & 2011 & database research \\
\hline UK & NR & $\mathrm{Ca}$ & dog - Labrador retriever & 1 & 2011 & database research \\
\hline UK & NR & $\mathrm{Ca}$ & dog - Rhodesian ridgeback & 1 & 2011 & database research \\
\hline NR & NR & $\mathrm{Ca}$ & $\operatorname{dog}$ & 5 & 2012 & database research \\
\hline UK & NR & $\mathrm{Ca}$ & $\operatorname{dog}$ & 1 & 2012 & database research \\
\hline UK & NR & $\mathrm{Ca}$ & dog - border collie & 1 & 2012 & database research \\
\hline UK & NR & $\mathrm{Ca}$ & dog - collie & 1 & 2012 & database research \\
\hline UK & NR & $\mathrm{Ca}$ & dog - collie & 1 & 2012 & database research \\
\hline UK & NR & $\mathrm{Ca}$ & dog - Labrador retriever & 1 & 2012 & database research \\
\hline UK & NR & $\mathrm{Ca}$ & dog - border collie & 1 & 2013 & database research \\
\hline UK & NR & $\mathrm{Ca}$ & dog-collie & 1 & 2013 & database research \\
\hline UK & NR & $\mathrm{Ca}$ & dog-dachshund & 1 & 2013 & database research \\
\hline UK & NR & $\mathrm{Ca}$ & $\operatorname{dog}$ & 1 & 2016 & database research \\
\hline UK & NR & $\mathrm{Ca}$ & dog-border collie & 1 & 2016 & database research \\
\hline UK & NR & $\mathrm{Ca}$ & dog - German shepherd & 1 & 2016 & database research \\
\hline NR & NR & $\mathrm{Ca}$ & dog-smooth collie & 2 & 2016 & database research \\
\hline US & Washington & $\mathrm{Ca}$ & $\operatorname{dog}$ & 5 & 2017 & pet food recall \\
\hline
\end{tabular}




\begin{tabular}{|c|c|c|c|c|c|c|}
\hline Country & $\begin{array}{l}\text { Poisoning } \\
\text { location }\end{array}$ & $\begin{array}{l}\text { Animal } \\
\text { category }\end{array}$ & Species & $\begin{array}{l}\text { Animals } \\
\text { affected }\end{array}$ & Year & Source \\
\hline UK & NR & $\mathrm{Ca}$ & dog-collie & 1 & 2017 & database research \\
\hline UK & NR & $\mathrm{Ca}$ & dog-collie & 1 & 2017 & database research \\
\hline UK & NR & $\mathrm{Ca}$ & dog - collie & 1 & 2017 & database research \\
\hline US & NR & $\mathrm{Ca}$ & dog & 1 & NR & pet food recall \\
\hline US & NR & $\mathrm{Ca}$ & dog & 1 & NR & pet food recall \\
\hline US & NR & $\mathrm{Ca}$ & $\operatorname{dog}$ & 1 & NR & pet food recall \\
\hline US & NR & $\mathrm{Ca}$ & dog - Labrador retriever & 1 & NR & database research \\
\hline US & NR & $\mathrm{Ca}$ & dog - pug & 6 & NR & pet food recall \\
\hline UK & NR & $\mathrm{Cc}$ & tiger (Panthera tigris) & 1 & 2004 & database research \\
\hline UK & NR & $\mathrm{Cc}$ & Amur tiger (P. tigris altaica) & 2 & 2009 & zoo questionnaire \\
\hline US & Nevada & $\mathrm{Cc}$ & $\begin{array}{l}\text { tiger (P. tigris) } \\
\text { cheetah (Acinonyx jubatus) } \\
\text { wolf (Canis lupus) }\end{array}$ & 3 & 2015 & personal communication \\
\hline US & Alaska & W & bald eagle (Haliaeetus leucocephalus) & 13 & 1986 & database research \\
\hline US & Alaska & W & bald eagle & 2 & 1987 & database research \\
\hline US & Florida & W & bald eagle & 1 & 1991 & database research \\
\hline US & Colorado & W & bald eagle & 3 & 1991 & database research \\
\hline US & Washington & W & $\begin{array}{l}\text { bald eagle, } \\
\text { golden eagle (Aquila chrysaetos) }\end{array}$ & 5 & 1991 & database research \\
\hline US & Alaska & W & bald eagle & 3 & 1993 & database research \\
\hline US & Alaska & W & bald eagle & 2 & 1993 & database research \\
\hline US & Florida & W & bald eagle & 9 & 1996 & database research \\
\hline US & various & W & bald eagle & 3 & 1997 & database research \\
\hline US & Colorado & W & bald eagle, golden eagle & 7 & 1999 & JAVMA \\
\hline US & Virginia & W & bald eagle & 1 & 2000 & database research \\
\hline CA & NR & W & eagle (Accipitridae) & 3 & 2000 & wildlife rehabilitation questionnaire \\
\hline FR & $\mathrm{NR}$ & W & griffon vulture (Gyps fulvus) & 3 & 2000 & personal communication \\
\hline US & South Carolina & w & bald eagle & 1 & 2001 & database research \\
\hline CA & Alberta & W & bald eagle & 4 & 2005 & database research \\
\hline US & Alaska & W & bald eagle & 6 & 2008 & database research \\
\hline FR & NR & W & griffon vulture & 9 & 2008 & personal communication \\
\hline US & Florida & W & wood stork (Mycteria americana) & 17 & 2010 & database research \\
\hline US & Maine & W & bald eagle & 1 & 2012 & personal communication \\
\hline US & Maine & W & bald eagle & 1 & 2014 & personal communication \\
\hline US & Maine & W & bald eagle & 1 & 2014 & personal communication \\
\hline US & Maine & W & bald eagle & 1 & 2014 & personal communication \\
\hline US & Maine & W & bald eagle & 2 & 2014 & personal communication \\
\hline US & Virginia & W & bald eagle & 2 & 2014 & personal communication \\
\hline UK & Northern Ireland & W & red kite (Milvus milvus) & 1 & 2014 & database research \\
\hline US & Maine & W & bald eagle & 1 & 2017 & personal communication \\
\hline CA & British Columbia & W & bald eagle & 26 & NR & personal communication \\
\hline CA & British Columbia & W & bald eagle & 5 & NR & personal communication \\
\hline US & Florida & W & bald eagle & 1 & NR & personal communication \\
\hline CA & Yukon & W & bald eagle & 1 & NR & personal communication \\
\hline CA & Ontario & W & bald eagle & 1 & NR & personal communication \\
\hline NR & NR & W & bald eagle & 1 & NR & personal communication \\
\hline NR & NR & W & bald eagle & 1 & NR & personal communication \\
\hline CA & British Columbia & W & bald eagle, coyote (Canis latrans) & 4 & NR & wildlife rehabilitation questionnaire \\
\hline CA & British Columbia & W & bald eagle, crow (Corvus spp.) & 5 & NR & personal communication \\
\hline UK & NR & W & fox (Vulpes vulpes) & 1 & NR & personal communication \\
\hline
\end{tabular}

UK, United Kingdom; US, United States; CA, Canada; FR, France; Ca, companion animal; Cc, captive carnivore; W, scavenging wildlife;

$\mathrm{NR}$, not reported or insufficient information provided to make a determination. 


\section{Which types of animals are most susceptible to exposure and poisoning?}

The most substantial proportion of individual poisoning cases $(59 \% ; 74 / 125)$ collated for this review (Tables 1 and 2) were reported for companion animals, almost exclusively dogs (Figure 1) and many of them working breeds (e.g., border collies). Scavenging wildlife were represented in $34 \%$ (43/125) of collated cases, and captive carnivores in 5.6\% (7/125). However, if considering the total number of animals affected across cases, more members of scavenging wildlife species were proportionately affected (in the wild) than companion animals ( $n=232$ versus 184 , respectively).

Most of the wild animals reported as having been poisoned by pentobarbital were scavenging bird species, $86 \%$ involving species in the eagle family (Accipitridae), with $73 \%$ of cases affecting bald eagles (H. leucocephalus; Tables 1 and 2). Other affected species included griffon vultures (Gyps fulvus), red kite (Milvus milvus) and wood stork (Mycteria americana). A lower tolerance of barbiturate concentrations, an affinity for scavenging soft tissues, group/communal feeding behavior, stealing of food from others (i.e., piracy) and the tendency for immature birds to feed at landfill sites are all factors which may influence poisoning of wild birds (Elliot et al. 2006, Langelier 1993, Thomas 1999).

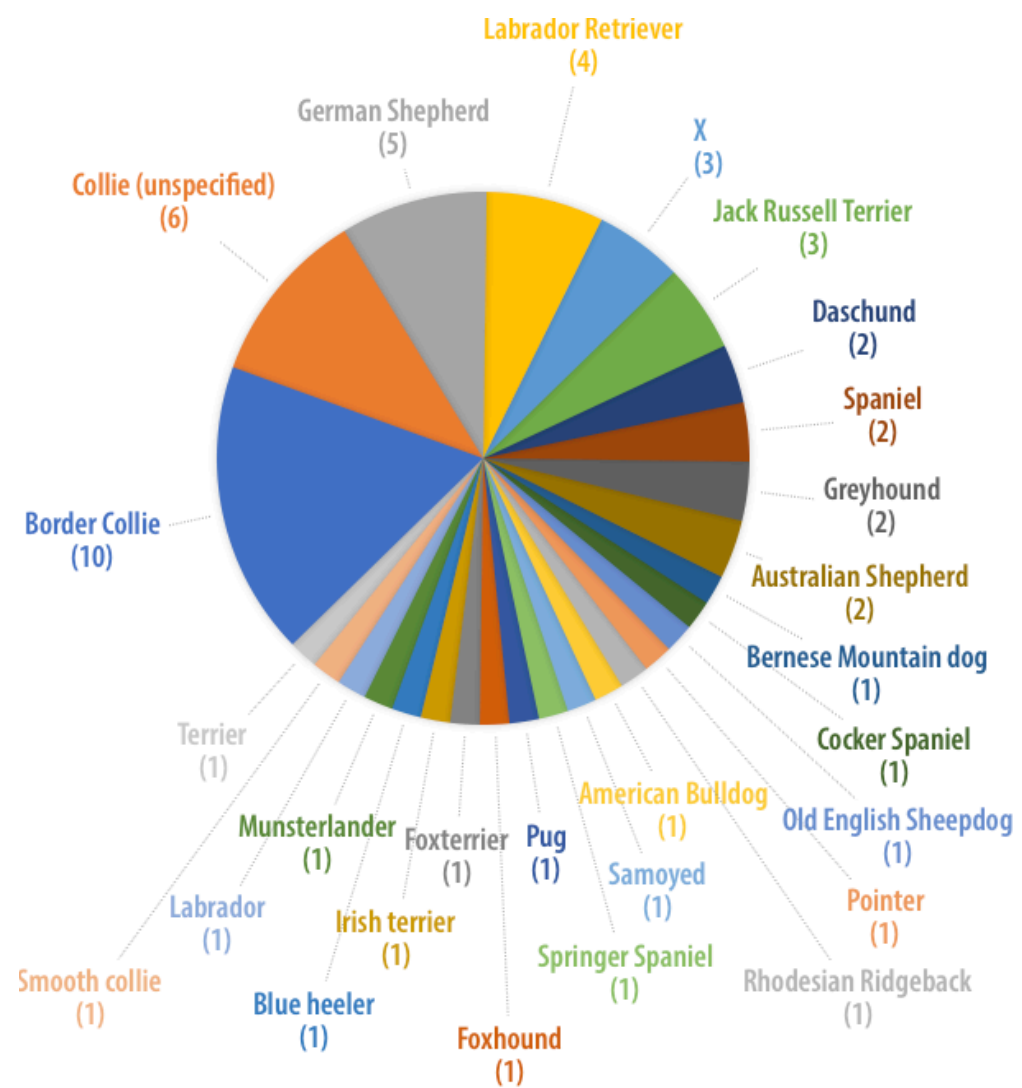

FIGURE 1-Dog breeds affected by secondary pentobarbital poisoning

TABLE 3-Conservation status of species secondarily exposed to pentobarbital residues, consolidated from existing literature, questionnaires, database search, personal communications

\begin{tabular}{|c|c|c|c|c|c|}
\hline Species & $\begin{array}{l}\text { Cases } \\
\text { affecting } \\
\text { species }\end{array}$ & $\begin{array}{l}\text { Total } \\
\text { affected } \\
\text { animals }\end{array}$ & $\begin{array}{l}\text { IUCN Red List } \\
\text { conservation status }\end{array}$ & $\begin{array}{l}\text { IUCN Red List } \\
\text { current population } \\
\text { trend }\end{array}$ & Reference \\
\hline pet dogs (Canis familiaris) & 72 & 182 & NA & NA & NA \\
\hline pet cats (Felis catus) & 2 & 2 & NA & NA & NA \\
\hline bald eagle (Haliaeetus leucocephalus) & $35^{\mathrm{a}}$ & 185 & least concern & increasing & BirdLife International (2016a) \\
\hline golden eagle (Aquila chrysaetos) & $3^{a}$ & 9 & least concern & stable & BirdLife International (2016b) \\
\hline eagles (unspecified Accipitridae) & 3 & 5 & NA & NA & NA \\
\hline griffon vulture (Gyps fulvus) & 2 & 12 & least concern & increasing & BirdLife International (2017a) \\
\hline red kite (Milvus milvus) & 1 & 1 & near threatened & decreasing & BirdLife International (2017b) \\
\hline wood stork (Mycteria americana) & 1 & 17 & least concern & decreasing & BirdLife International (2016c) \\
\hline American crow (Corvus brachyrhynchos) & $1^{\mathrm{a}}$ & 1 & least concern & increasing & BirdLife International (2018) \\
\hline coyote (Canis latrans) & $1^{\mathrm{a}}$ & NR & least concern & increasing & Gese et al. (2008) \\
\hline red fox (Vulpes vulpes) & 1 & 1 & least concern & stable & Hoffman et al. (2016) \\
\hline tiger (Panthera tigris), captive & $5^{a}$ & 10 & endangered & decreasing & Goodrich et al. (2015) \\
\hline cougar (Puma concolor), captive & 1 & 3 & least concern & decreasing & Nielsen et al. (2015) \\
\hline lion (Panthera leo), captive & 1 & 1 & vulnerable & decreasing & Bauer et al. (2016) \\
\hline cheetah (Acinonyx jubatus), captive & $1^{a}$ & 1 & vulnerable & decreasing & Durant et al. (2015) \\
\hline wolf (Canis lupus), captive & $1^{a}$ & 1 & least concern & stable & Mech and Boitani (2010) \\
\hline
\end{tabular}

NA, not applicable, i.e., conservation status not conferred on this species; NR, not reported or insufficient information provided to make a determination.

a. Secondary poisoning cases in which additional species also were reported to have been affected.

b. Estimated number of cases $=125$. The total in this table appears elevated due to duplication, from poisoning instances where multiple species, rather than a single species, were affected. 
In $79 \%$ of the estimated 125 poisoning cases, the source (i.e., euthanized) carcass was that of a livestock animal. The livestock carcasses most commonly at the root of poisoning cases were: sheep (Ovis aries; 35\%), horses (Equus caballus; 28\%) and cattle (Bos taurus; 24\%). Other kinds of livestock source animals recorded included: chickens (Gallus gallus domesticus), pigs (Sus scrofa), goats (Capra aegagrus hircus) and a mule (Equus asinus $\times$ E. caballus). In all instances of recorded poisonings of captive carnivores, livestock were the source carcasses. In $15 \%$ of cases, the source was a companion animal carcass, and in $6 \%$ a wild animal (e.g., a euthanized deer) that was left uncovered.

Of these, sufficient data from 36 of the 49 cases affecting companion animals allowed further analysis of percentage mortality, with more than $90 \%$ of the exposed animals surviving. Conversely, in 24 of the 39 cases affecting scavenging wildlife, less than $10 \%$ of the animals affected survived the pentobarbital poisoning (Figure 1). While the average number of animals affected in each exposure incident (i.e., per case) differed between wild, companion and captive animals (5.5, 2.5, 2.3; respectively), application of an ANOVA determined that the influence of 'animal type' on the observed differences was statistically insignificant $(f=2.06, d f=2, P=0.13)$. This conclusion seemed at odds with what is known about the ecology, natural history and communal (or solitary) nature of some wild scavengers. Indeed, excluding captive animals and companion animals directly fed tainted food by owners to focus on wild-occurring incidents only, there is a significant difference in the reported numbers of companion animals affected per incident and the reported numbers of wild animals affected per incident $(P=0.0006)$. This finding is more in line with the overall observation of multiple incidences of singular or low numbers of $\mathrm{dog}$ and canid poisonings, versus comparatively larger numbers of communal avian scavengers (e.g., eagles) being affected per incident.

Depending upon the population status of the affected wild or captive species, and where the loss of even a single individual could be a setback to captive breeding efforts or the wild population (Table 3), the ensuing repercussions from an incident could have biological or ecological significance. Excluded from these three tables, but noteworthy, are species occasionally mentioned anecdotally as having been exposed (e.g., in the oftencited Krueger and Krueger, 2002), but for which no corroborating literature could be traced. These 'anecdotally affected' species include ravens (Corvus corax), magpies (Pica pica), gulls (Laridae), martens (Martes spp.), fishers (Pekania pennanti), lynx (Lynx spp.), bobcats (Lynx rufus), bears (Ursidae) and otters (Lutrinae).

\section{What level of awareness exists among veterinary practitioners and animal caregivers on this issue?}

In the UK, veterinarians and Royal Society for the Prevention of Cruelty to Animals (RSPCA) inspectors have access to pentobarbital for euthanasia procedures (RCVS 2012a). The Royal College of Veterinary Surgeons (RCVS) guidelines advise that these 'approved users' discuss carcass disposal options with the animal's owner (RCVS 2012b). In 2003, the US Food and Drug Administration's (FDA) Center for Veterinary Medicine added warning language to pentobarbital euthanasia drug labels, stating: "This product is toxic to wildlife. Birds and mammals feeding on treated animals may be killed. Euthanized animals must be properly disposed of by deep burial, incineration, or other method in compliance with state and local laws, to prevent consumption of carcass material by scavenging wildlife." An examination of the cases collated in Tables 1 and 2 show numerous poisoning incidents have occurred since then, contributing to the perception that incidents of secondary poisoning widely persist due to lack of awareness around this issue (e.g., Taggart et al. 2015). Gathering supplementary information around the reasons for this persistence in lack of awareness was one of the main drivers of this research.

The questionnaire inquired: "Has your organization encountered any cases of secondary pentobarbital poisoning, whether through word of mouth, direct admissions [of animals into the facility] or accidental exposure in captivity?". Based on the 26 responses obtained from veterinary surgical and wildlife rehabilitation centers, and zoos, a measure of overall awareness of secondary pentobarbital toxicity was assigned, from one of four categories:

1) Completely unaware, wherein respondent did not indicate familiarity with the concept of pentobarbital poisoning and respondent's facility has no safety precautions whatsoever (for product or carcass) in place: 10 (38\%).

2) Moderately aware, with basic mitigation; for example, have specialized disposal bins for used pentobarbital product containers: 7 (27\%).

3) Aware, with basic mitigation, wherein respondent seemed fully informed and familiar with pentobarbital poisoning, but associated facility lacks adequate procedures related to product or carcass disposal: 5 (19\%).

4) Aware, with appropriate mitigation, wherein facility had secure product storage and carcass tagging protocol: $3 / 25$ rather than $26(12 \%)$ due to insufficient information being provided by one of the respondents.

The questionnaire responses, albeit from a relatively small sample size (26/565), provided a valuable snapshot of practices and perceptions. To these results, however, we add the caveat that level of awareness regarding the risks posed by pentobarbital residues at any particular facility may be utterly unrelated to the rate of encounter of secondary poisoning incidents there. In other words, respondents who showed a high(er) level of awareness, and in whose facility there were appropriate mitigation measures in place, may be as likely to encounter a pentobarbital poisoning case as those at facilities where personnel are unaware of the risk.

Awareness of the issue may coincide with, but not necessarily have led to, the implementation of tailored mitigation measures. Where questionnaire respondents indicated that appropriate clinical response protocols that would prevent pentobarbital poisoning were in effect at their facility, these protocols were not explicitly put in place to do so, which is an important distinction. Though potentially difficult to measure, actual differences in levels of awareness between facilities might manifest instead in the form of early diagnosis of secondary pentobarbital exposure, followed by rapid treatment (and ideally recovery), or in single/ multiple/repeated instances of inadvertent poisoning in-house, through procurement and feeding of tainted carcasses. Further, there may exist discrepancies in levels of awareness in-house, amongst facility personnel and associated volunteers, each having different roles and responsibilities concerning the animals under care. Such seemingly disparate factors are reflected in Table 4, which summarizes the number of respondents from the various 
facilities having encountered/confirmed poisoning cases, relative to their associated level of awareness. While the questionnaire for this review was devised for exploratory purposes, further questionnaires could be designed and implemented to parse out these aforementioned differences fully. Fundamentally, any clinical response will be reactive, whereas the core issue of appropriate and safe euthanized animal carcass disposal remains the core preventive issue.

TABLE 4-Level of awareness in 26 questionnaire respondents about potential secondary pentobarbital poisoning relative to facilities with confirmed poisoning cases

\begin{tabular}{|c|c|c|c|}
\hline Questionnaire item & $\begin{array}{l}Z \\
(n=5)^{a}\end{array}$ & $\begin{array}{l}\text { VS } \\
(n=10)^{\mathrm{a}}\end{array}$ & $\begin{array}{l}\text { WR } \\
(n=11)^{\mathrm{a}}\end{array}$ \\
\hline \multirow{2}{*}{$\begin{array}{l}\text { Of all respondents, those having } \\
\text { encountered secondary pentobarbital } \\
\text { poisonings at their facility }\end{array}$} & $1^{b}$ & $1^{b}$ & $1^{b}$ \\
\hline & $1^{c}$ & $4^{c}$ & $3^{c}$ \\
\hline $\begin{array}{l}\text { Respondents unaware that secondary } \\
\text { poisoning could occur }\end{array}$ & 2 & 3 & 5 \\
\hline $\begin{array}{l}\text { Respondents with appropriate mitigation } \\
\text { measures in place }\end{array}$ & 2 & $0^{d}$ & 1 \\
\hline
\end{tabular}

$Z$, zoos; VS, veterinary surgical centers; WR, wildlife rehabilitation centers. a. Total number of questionnaire respondents from these facilities.

b. Suspected or unconfirmed cases of pentobarbital poisoning.

c. Confirmed cases of pentobarbital poisoning.

d. Did not respond to the question or had not encountered secondary poisoning.

TABLE 5-Euthanized animal carcass disposal methods and number of related poisoning cases, as compared to the number of questionnaire respondents indicating their use of these methods

\begin{tabular}{lll}
\hline Disposal method & $\begin{array}{l}\text { Associated } \\
\text { poisoning cases }\end{array}$ & $\begin{array}{l}\text { Questionnaire respondents } \\
\text { using this disposal method }\end{array}$ \\
\hline uncovered & 25 & $0^{\mathrm{b}}$ \\
fed (to other animals) & 19 & 1 (Z: 1, VS: 0, WR: 0) \\
buriedc & 12 & 6 (Z: 1, VS: 5, WR: 0) \\
burned & 6 & 0 \\
landfill & 4 & 0 \\
rendered & 3 & 1 (Z: 0, VS: 0, WR: 1) \\
incineration & 0 & 21 (Z: 5, VS: 9, WR: 7) \\
donated & 0 & 7 (Z: 2, VS: 0, WR: 5) \\
not statede & 57 & 1 (Z: 0, VS: 1, WR: 0 \\
\hline Total & $125^{\mathrm{a}}$ & $37^{\mathrm{f}}$ (Z: 9, VS: 15, WR: 13)
\end{tabular}

Z, zoos; VS, veterinary surgical centers; WR, wild life rehabilitation centers.

a. Identified and tallied across published/reported cases and from questionnaire responses

b. $0=$ none of the questionnaire respondents stated this category as the mode of disposal used in their practice

c. The disposal method of returning an animal to the owner for burial is pooled within this category

d. Donated to museums, universities or laboratories for research purposes

e. Insufficient information available in the case or from questionnaire respondent

f. While the total number of questionnaire respondents was 26 , this higher tally indicates some facilities may use multiple methods for euthanized animal carcass disposal

\section{How are the carcasses of various types of euthanized animals disposed of, and how are these disposal methods associated with secondary poisoning incidents?}

When an incident of secondary poisoning is reported, identifying the carcass disposal method(s) at the root of its occurrence and understanding the reason(s) for their use is crucial for future prevention. Across the available literature, and based on questionnaire responses and other forms of inquiry, eight methods for disposing of euthanized animal carcasses were identified. Table 5 contrasts the number of poisoning cases associated with a given disposal method against the number of questionnaire respondents indicating its use at their facilities, further elucidating disposal methods not associated with poisoning incidents (e.g., incineration and donation to museums or laboratories. In the present review, none of the questionnaire respondents indicated disposal at a landfill as a method employed at their facility. However, we are aware from the literature and separate personal communications with colleagues within the wildlife rehabilitation community (i.e., by N. Richards) that some facilities (e.g., veterinary) do indeed dispose of euthanized animal carcasses at landfill, which in turn has resulted in secondary poisoning (e.g., of bald eagles, in a 2015 Florida case). If anything, the information summarized in Table 5 (and in Table 4) reflects the current disparity in euthanized animal carcass disposal practices and need for further uniform awareness.

Here, we briefly discuss in turn some of the most prevalent forms of disposal in relation to incidents of secondary pentobarbital poisoning. Time of year and seasonality are underlying influences on the feasibility of using specific carcass disposal methods, while potentially reducing the effectiveness of others. This section concludes with a consideration of research underway to assess the viability of composting euthanized animal carcasses as a possible safe alternative to currently used disposal methods.

Placement outside uncovered-Reasons for intentionally leaving euthanized animal carcasses uncovered over other means of disposal include the usually benevolent intent to feed scavenging wildlife, a frequently cited example of this being the unintentional poisoning of 29 bald eagles that fed on the carcass of a euthanized cow purposefully left out for them by a Canadian farmer (Langelier 1993). Similar anecdotal accounts received via personal communications include the discarding of euthanized deer (Cervidae) by the roadside and chickens (G. gallus domesticus) left out for foxes ( $V$. vulpes) to consume. The expense of large animal disposal and the difficulty of excavating frozen ground also have been given as impediments to attempting or attaining recommended burial depths (Thomas 1999, Langelier 1993).

Burial and disposal at landfill-Burial is widely considered a suitable method for disposing of euthanized animal carcasses (Leary et al. 2013). Correspondingly, when animal poisoning incidents arise following exposure to an ostensibly buried carcass, the implication is that an appropriate standard of disposal was not met (Brakes and Smith 2005). Some of the personal communications conducted for this review yielded related accounts such as foxes ( $V$. vulpes) being poisoned after unearthing euthanized companion animals in the UK (RSPCA). An incident in the US in which a bear and her two cubs unearthed a carcass at a landfill site and were subsequently poisoned has sometimes been mentioned in this context, though this case is anecdotally 
attributed to a now-retired wildlife agent and could not be traced to a report or literature reference. Yet in a review of bald and golden eagle mortality submitted to the NWHC between 1975 and 2013, through which 36 eagle deaths (33 bald, 3 golden) were determined to have been secondarily exposed to pentobarbital, people had in most of these cases attempted to dispose of the source carcass in the 'correct' manner (Russell and Franson 2014).

Indeed, discrepancies exist in the interpretation of what constitutes a 'safe' burial depth within the associated standards and guidelines, with underlying assumptions often made that risks are being managed somewhere along the chain of supply or disposal. Although veterinarians are required to convey to their clients the importance of safe burial depth (Gonzales and Clifford 2015), and while the United States Fish and Wildlife Service (USFWS) and other entities have suggested approximately 1-2 meters, no specific burial depth requirements for euthanized animal carcasses have been collectively discussed or agreed between members of the veterinary and animal care community, municipal or landfill managers, wildlife protection agents, and other key stakeholders.

Regarding the influence of seasonality, insufficiently buried carcasses thaw in spring, becoming accessible to scavengers at a time coinciding with reduced food availability (Langelier 1993). Carcass bins at landfill sites, which have been successfully used in some US states (e.g., Alaska) may effectively prevent wildlife scavenging (Jozwiak 2009). Similarly, the use of secure bags following euthanasia would reduce the accessibility of euthanized animals, even if otherwise left uncovered. However, to this consideration, we add that research has documented the longterm persistence of pentobarbital residues in the tissues and organs of euthanized animals (for 220 days or more; Payne et al. 2012). Two US-based cases in point: a dog was temporarily intoxicated after scavenging on a goat that had been euthanized then buried at least 47 days prior (as discussed in Campbell et al. 2009), and two dogs were poisoned after feeding on the carcass of a horse that had been euthanized more than two years before (Kaiser et al. 2010). Also refer to the above description of anecdotal information from a 2007 case where two dogs were secondarily poisoned after excavating and feeding on the bones of a horse that had presumably been euthanized then buried for ten years.

Ideally, regulations and guidelines could be further tailored to the ecology of the local area, the traits of known scavenger species, and the season. In a broader sense, improving the procedures for the disposal of animal carcasses would benefit ecosystems by lessening barbiturate leachate contamination of water sources mostly from landfill sites (Peschka et al. 2006, Emke et al. 2011) reducing the risk of poisoning by other veterinary drugs, and limiting the risk of spread of pathogens (Dubie et al. 2017). Exposure to euthanized carcasses could be restricted and impeded by appropriate bins and bags; however, the more significant issue of residue persistence, and potentially, seepage from these receptacles, remains unresolved overall. In colder regions, difficulties in meeting burial depths should be accounted for; with compulsory incineration in winter months as a potential solution.

Incineration versus burning-Incineration has been deemed an appropriate alternative to burial (Krueger and Krueger 2002). No instances of its use were reported in the published literature, although most (57\%) questionnaire respondents reported disposing of euthanized animal carcasses by incineration (see Table 5). The process of incineration (a dedicated waste treatment method wherein carcasses are subjected to high-temperature combustion and wholly converted to ash) is sometimes conflated with burning, and there exists a misconception that less expensive alternatives (e.g., outdoor burning) are sufficient for safe carcass disposal. Companion animals and wildlife have foraged charred carcasses from bonfires on numerous occasions, and become debilitated as, for example, documented by VPIS, when a German shepherd scavenged the carcass of a euthanized sheep from a UK farmer's bonfire in 2016. Similarly, cooking tainted meat does not remove or 'nullify' pentobarbital residues, a practice which also has led to the poisoning of dogs in the past (Reid 1978).

Rendering-The rendering process converts waste animal tissue into stable products (e.g., meat and bone meal), either with boiling water or steam or by dry heating, in discrete batches or as a continuous process. Pentobarbital residues may persist in tissues rendered from euthanized animals, which has led the American Veterinary Medical Association (AVMA) to determine that rendering byproducts from pentobarbital-euthanized animals are inherently hazardous for incorporation into pet food. Nonetheless, pet food products continue to be recalled following poisoning incidents stemming from the presence of residues (FDA 2017). In this regard, hazardous material and carcass tracking labels could help to limit the processing of contaminated carcasses in rendering facilities, reducing the necessity in future of recalling pet food products. Separately, at a more fundamental level, perceptions that the process of rendering makes pentobarbital-tainted tissues safe, remain to be addressed and resolved.

Composting, an alternative disposal method under investigationNot yet fully discussed as a euthanized animal carcass management method per se (but see Shearer et al. 2018), the feasibility of using composting as an alternate and safer method of disposal is currently being investigated by a US-based team of agricultural researchers. In the state of Oklahoma, the monitoring of pentobarbital residue concentration in the tissues of euthanized horses in compost piles has yielded mixed results (Payne et al. 2012). Liver tissue removed from equine carcasses after 224 days of composting contained measurable pentobarbital residues, though the authors maintain that the (unspecified) detected concentration was sufficiently low to be deemed safe (Ciamillo et al. 2014). If the method can be refined, the intent is to promote composting as cost-effective and bio-secure disposal alternative.

Special considerations for third-party disposal, and remote or private lands - In the UK, organizations sending animal carcasses for third party disposal (e.g., the National Fallen Stock Company) must follow requirements for "safe storage, coverage and transportation beyond those discussed with individuals" (DEFRA 2012). Euthanized companion animals, equines, and wild animals may be buried on the owner's land. However, government guidelines prohibit burning carcasses, feeding carcasses to other animals, and burying livestock on an owner's land unless the area is deemed 'remote' (DEFRA 2012). These particular guidelines currently state that 'renderers' and 'hunt kennels' are appropriate disposal destinations, and do not implicitly notify the 'user' that consumption of euthanized carcasses by other animals can harm them (DEFRA 2012). Whether or not relaxed disposal regulations in remote areas increases the likelihood of secondary poisoning is currently unclear, but seems worthy of further verification, in 
parallel with the fact that secondary poisoning in remote areas may currently be underreported (Shore et al. 2014, and as discussed below in the monitoring measures section). Alternative euthanasia methods (e.g., mechanical methods, providing they do not carry additional human and animal welfare risks) could perhaps minimize exposure risks particular to remote areas (Krueger and Krueger 2002, Shearer et al. 2018) while further monitoring of fallen stock services could prevent the accidental provision of tainted carcasses.

\section{Where do facilities source carcasses for provisioning captive wildlife and other animals, and how is the safety of those carcasses assured? What can be the outcome of not enacting safety protocols and verification?}

Within the collated published cases, feeding euthanized animal carcasses to other animals was reported as the second most frequent means of disposal (Table 5). Passing mentions in the literature and during personal communications revealed more specifically the feeding of euthanized animals to raptors in UK rehabilitation centers and to circus animals. Captive animals, particularly endangered species, are purportedly fed under strict safety guidelines (Maslanka et al. 2013, NAG 2017, Stetler 2011, Zorrilla et al. 2018), which could account for the relatively small number of barbiturate poisoning cases documented (16 of 432 animals, or $3.7 \%$; Tables 1 and 2).

However, in questionnaire responses, zoo representatives acknowledged that they did provision carcasses, including some animals that may have been euthanized, without carrying out (or the requirement to conduct) residue testing before feeding. This lack of testing is despite several husbandry guidelines that identify exposure to barbiturates as the most common form of poisoning in captive felids (AZA n.d., AZA 2016). Of the zoos and rehabilitation facilities which indicated that they feed carcasses to other animals, $26 \%$ were found to be reliant upon supplier quality assurance (i.e., certification, oral assurance) to ensure safety for consumption. The carcasses were sourced from hunters, supermarkets, laboratories, farms, public donations, fisheries, and roadkill collection. A further $21 \%$ of respondents had enacted euthanasia restrictions (e.g., refusing to accept euthanized animal carcasses), while $37 \%$ did not specifically mention having a safety protocol in place.

Captive wildlife represents a particular poisoning and vulnerability context, wherein many species are housed due to declining numbers and precipitous population stability in the wild (see Table 3), and as part of breeding efforts for eventual release, to conserve the species and repopulate local wild populations (Zorrilla et al. 2018). Even the loss of a single individual from an endangered species can impact on already fragile populations, as illustrated by the virtual extinction of Gyps vultures on the Asian subcontinent following exposure to the NSAID diclofenac, and subsequent efforts to stabilize the population, which included removal of birds from the wild for captive rearing and breeding until their environment was deemed safe for them to be released (Richards et al. 2017). The success of these and similar population stabilization efforts depends partially upon the careful provision of animal carcasses free from harmful veterinary drug residues, including pentobarbital, both to captive and wild birds (Shultz et al. 2004, Hewitt et al. 2010, Boshoff et al. 2011, Zorrilla et al. 2018).
Mortality in captive carnivores disrupts carefully planned captive propagation programs, and the loss of genetic diversity threatens the viability of fragmented wild populations (Jiang et al. 2007). In this regard, felids seem to have been particularly affected. Members of this family poisoned in captivity by pentobarbital include: Sumatran ( $P$. tigris sumatrae) and Amur tigers ( $P$. tigris altaica), categorized by the International Union for Conservation of Nature (IUCN) as Critically Endangered and Endangered respectively (Linkie et al. 2008, Miquelle et al. 2011; Table 3). In 1990, a lioness ( $P$. leo) died from pentobarbital poisoning, also having been poisoned but successfully treated 18 months before (Verster et al. 1990). In 2011, three tigers (P. tigris) were reportedly poisoned at a zoo in South Africa (Williams et al. 2011), and in 2015, at a wildlife sanctuary in Nevada (US) a tiger (and a wolf [Canis lupus]) died and a cheetah (A. jubatus) was intoxicated after they were accidentally fed meat from a pentobarbital-euthanized horse (Corona 2015).

Private zoos, kennels and feeding stations for endangered red kite (M. milvus) also source carcass meat. A poisoning case affecting a red kite (Table 2) was reported from Northern Ireland. Again, even a single case like this could impact a rare species reintroduction program: at the time (July 2014), Northern Ireland had 16 breeding pairs of kites, of which eight had successfully reared offspring (RSPB b).

Companion animals housed in captivity also have been adversely affected by the provision of tainted carcass meat. For example, numerous hunt kennels in the UK operate fallen stock collection services, whereby they can receive, or collect, donations of dead animals. Our research collated multiple reports involving the accidental pentobarbital poisoning of foxhounds, fox terriers, and greyhounds (C. lupus familiaris) fed tainted carcass meat (Tables 1 and 2). In one such case, 70 foxhounds were fed raw meat from a horse that had been euthanized with pentobarbital (Table 1). Two of these dogs died, while 10 exhibited severe clinical signs (e.g., ataxia, lethargy), though they eventually recovered.

\section{What monitoring measures are currently in place for detecting secondary pentobarbital poisoning cases, and which factors influence detection and reporting rates?}

A range of initiatives has been implemented to monitor and document the myriad causes of poisoning in wildlife, with an overarching aim of providing robust data to support ongoing risk mitigation within broader conservation efforts. For this review, the UKs Wildlife Case Investigation Scheme and Veterinary Poisons Information Service, and the US-based National Wildlife Health Center were consulted. Through our research, we became aware that at present neither debilitated living animals or carcasses are typically screened for pentobarbital residues routinely or opportunistically (Shore et al. 2014), nor is there a centralized database to monitor or, where applicable, link occurrence of pentobarbital poisoning incidents. The absence of screening and monitoring is noteworthy because wild animals may feed on a tainted carcass then disperse, reducing their likelihood of discovery, particularly in remote areas (Shore et al. 2014, Thomas 1999). Without a centralized database, such solitary deaths or cases of debilitation may go undetected, fail to be attributed to pentobarbital exposure, or fail to be tallied as part of or linked to a more widespread incident of poisoning. 
Pentobarbital-intoxicated animals may be predisposed to post-exposure trauma (e.g., motor vehicle collision or predation), which can mask the underlying cause of sub-lethal impairment (Jozwiak 2009). Additional examples include intoxicated eagles found debilitated on railway tracks or drowned (Thomas 1999). Similarly, some of the clinical signs and symptoms of pentobarbital poisoning may mirror those of other toxicants (e.g., lead, some pesticides) leading to erroneous diagnosis (Thomas 1999). A government-led investigation found that in 2004 the cause of death in $45 \%$ of wildlife poisoning cases in England remained unresolved, classed as 'poisoning by undetermined chemicals' (Barnett et al. 2005, DEFRA 2012). Likewise, records of raptor persecution in Scotland include only cases stemming from exposure to pesticides. If analysis for the focal pesticides is negative, no further testing of other toxicants that also could have caused mortality is conducted (RSPBa).

Through this research, we also learned that cases in which animals are determined to have been exposed to pentobarbital but recovered with treatment might not be reported as such or further investigated. In France, while the assessment of pentobarbital exposure in wildlife may be part of the routine screening of monitoring initiatives, such exposure is unlikely to be reported if the animal does not present clinical signs or if it recovers, even when pentobarbital residues are detected (Pinasseau 2015). This loss of information is two-pronged, wherein underreporting of actual pentobarbital poisoning data can lead to an underestimation of the risk, and in turn to a reduced impetus to review and modify protocols that could prevent future poisoning.

When incidents are reported, poisoning of companion animals is most frequently represented (Tables 1 and 2), likely because the proximal relationship between people and their pets ensures that symptoms are observed relatively soon after exposure, with subsequent rapid response in the form of treatment. In contrast, the poisoning of wildlife species seems to be particularly underreported, unless a) it has occurred in association with companion animal poisoning, b) the conspicuousness of multiple wildlife deaths attracts public attention (e.g., when 17 wood stork (M. americana) were poisoned in Florida in 2010; NWHC), c) there is a cultural affinity for the species (e.g., bald eagles), or d) if individual animals conspicuously forage near human habitation (e.g., Russell and Franson 2014).

Cases of avian or raptorial poisonings, it seems, are more likely to be reported than those of mammalian species, especially if the latter accorded low conservation status or priority (e.g., red fox [V. vulpes] and coyote [C. latrans]; Table 3). This disparity is further compounded if these animals are considered to be nuisance species (e.g., by homeowners and farmers) and further decreases the likelihood of poisoning incidents reporting (Hoffmann and Sillero-Zubiri 2016, Lehner 1976). Similarly, the carcasses of smaller animal scavengers (e.g., rodents) may simply not be detected or, particularly in the case of abundant species (e.g., corvids), not considered to represent a sufficiently significant ecological loss to pursue further, a phenomenon discussed more generally in Shore et al. (2014).

\section{Emerging areas of potential exposure or exposure prevention that require follow-up}

This section highlights information which came to light during this review and was deemed especially noteworthy. While some subjects that emerged from questionnaire responses and personal communications extended beyond the main aim and scope of the review, these contribute to the underlying issue of secondary pentobarbital poisoning and awareness around the risks and as such merit further exploration and consideration.

Emerging or unresolved sources of pentobarbital exposure-The deliberate use of pentobarbital as a poisoning agent, via bait material laced with the drug, has been documented in Spain (Sanchez-Barbudo et al. 2012). Notwithstanding that to date only a single case has been uncovered, this discovery should be sufficiently compelling to instigate routine monitoring, notably where deliberate poisoning of animals is a known practice, as in many parts of Europe (Guitart et al. 2010).

Bischoff et al. (2011) reported on a dog that evidently fed on tainted whale blubber encountered on a beach where, three weeks prior, a stranded juvenile humpback whale was euthanized and necropsied. Complete removal of the whale carcass was attempted but proved challenging. Samples of the dog's urine and from tissue recovered at the beach both tested positive for pentobarbital and the anticonvulsant phenytoin. The authors noted that while the dog was not determined with certainty to have ingested the pentobarbital-tainted blubber, it appeared to have been the likeliest source of exposure (Bischoff et al. 2011). A workshop summary report on humane euthanasia protocols for stranded cetaceans highlight that "when considering chemical euthanasia, it must be remembered that the size of the animal also necessitates large quantities of euthanasia agents" (IWC 2015). The effectiveness of pentobarbital as a humane euthanasia agent relative to other available methods (e.g., shooting) also are considered in this document.

Provisioning known euthanized animals, or dead animals of unknown/unconfirmed veterinary history (e.g., from laboratories, public donations, and fisheries) represents an unambiguous, unadvised exposure threat. For many questionnaire respondents, the primary method of ensuring safety and wholesomeness of carcasses obtained for feeding to captive carnivores was mainly reassurance from the supplier. The documented historical and recent reports of multiple zoos using animals euthanized by barbiturates to feed captive carnivores demonstrate that further actions are required (AZA 2016). Such action could include regular review of the supplier facility, euthanization labels on carcasses (e.g., some farms in the UK mark the ears of euthanized livestock), and the use of suppliers inspected by reputable authorities that conduct residue testing, although this service is not always available.

Similarly, the incorporation of rendered animal by-products in pet food remains an important issue to be resolved.

Discrepancies in pentobarbital solution dosage rates and corresponding differences in exposure and residue detection-The dosage administered, the concentration of the solution used, and by extension, the subsequent concentration of residues within the source carcass, vary according to the type and size of the euthanized animal. Subsequently, the quantity of residues 
ingested by a carnivore entirely depends on which tissues are consumed (e.g., the liver and heart will contain higher concentrations). These factors can in turn influence variations in the concentration of pentobarbital detected in plasma and serum of exposed animals within the same species (e.g., dogs). However, during the process of review we noted that amidst a smattering of reportings only, animals of the same species have been administered a range of pentobarbital solution concentrations for euthanasia (e.g., $10-30 \mathrm{~mL}$ for sheep). In relation to responsive treatment, Campbell et al. (2009) discussed how a solution comprising $429 \mathrm{mg} / \mathrm{kg}$ of sodium pentobarbital (and $55 \mathrm{mg} / \mathrm{kg}$ of phenytoin) was administered to a goat (ostensibly the source animal in the related poisoning of at least one $\mathrm{dog}$ ), but the manufacturer's suggested dose was much lower: $86 \mathrm{mg} / \mathrm{kg}$ of pentobarbital. Table 6 summarizes pentobarbital residue levels as measured in the source animal relative to residues detected in samples from affected animals, and their prognosis, while simultaneously illustrating how little information is currently available on this subject. Collation of data on serum and urine levels in exposed animals across the three target groups, and residue ranges detected within source carcasses, with associated dosage of the pentobarbital and anti-convulsant solution, would help guide risk assessments, treatment and rehabilitation plans, and better inform practitioners and those involved in monitoring efforts about the nature of exposure.

Procedures implemented for safe, secure storage of pentobarbital products-Beyond the scope of the current study, this is an area worthy of further inquiry and pursuit, and of additional relevance to environmental inputs. The questionnaire (Appendix) inquired, "Are there any special regulations or provisions related to the disposal of euthanized carcasses or euthanasia packaging, etc.?" Fifty-three percent (53\%) of questionnaire respondents stated that they used clinical waste bins to dispose of animal tissue, bodily fluids, drugs, and unspecified pharmaceutical products, syringes, and needles. Twenty-eight percent (28\%) of respondents said that they followed general, pre-set organizational or governmental guidelines for disposal of tissues and carcasses. None of the respondents identified the guidelines to which they were referring.

Broader consideration of risks posed by secondary exposure to barbiturates-The following question was asked to gain a broader sense of pentobarbital usage relative to other euthanasia methods: "In cases where non-inhalant, injectable pharmaceutical agents are used, which are most commonly administered [as a euthanasia method]?" Non-inhalant, injectable solutions were used by $72 \%$ of the respondents as the primary method of euthanasia, with $83 \%$ of those identified as a barbiturate, including secobarbital and phenobarbital, among others. Hewitt et al. (2010) reported on an incident of secobarbital poisoning in a captive Amur tiger $(P$. tigris altaica) that was unintentionally fed tainted horse meat. Expanding the focus from pentobarbital to more broadly investigating secondary exposure to barbiturates as a whole may generate further insight that more comprehensively elucidates the extent of this issue. Potential repercussions posed to companion animals, scavenging wildlife and captive carnivores from the anticonvulsants and other ingredients also present in barbiturate euthanasia solutions merits further evaluation.

TABLE 6-Variations reported in residual pentobarbital concentration in source animals and associated parameters in poisoned animals that fed on carcasses

\begin{tabular}{|c|c|c|c|c|c|c|c|}
\hline $\begin{array}{l}\text { Source } \\
\text { animal }\end{array}$ & $\begin{array}{l}\text { Concentration } \\
\text { in source animal } \\
\text { (standardized, } \\
\text { to } \mathrm{mg} / \mathrm{kg} \text { ) }\end{array}$ & $\begin{array}{l}\text { Sample tested } \\
\text { from source } \\
\text { animal }\end{array}$ & Poisoned animal & $\begin{array}{l}\text { Sample tested } \\
\text { from poisoned } \\
\text { animal }\end{array}$ & $\begin{array}{l}\text { Concentration } \\
\text { in sample } \\
\text { (standardized, } \\
\text { to } \mathrm{mg} / \mathrm{mL} \text { ) }\end{array}$ & $\begin{array}{l}\text { Outcome } \\
\text { for poisoned } \\
\text { animal(s) }\end{array}$ & Reference \\
\hline calf & $125-300$ & tissue & dog & urine & 0.136 & survived & Anderson et al. (1979) \\
\hline calf & NR & NR & dog & NR & NR & survived & VPIS \\
\hline calf & NR & NR & dog & NR & NR & survived & VPIS \\
\hline calf & NR & NR & dog & NR & NR & survived & VPIS \\
\hline chicken & 70 & tissue & dog & NR & NR & NR & VPIS \\
\hline chicken & $200^{\mathrm{a}}$ & tissue & puppy & NR & NR & NR & VPIS \\
\hline goat & $0.00125-0.003$ & tissue & dog & urine & NR & survived & Campbell et al. (2009) \\
\hline horse & NR & NR & dog & serum & 0.00028 & died & Polley (1977) \\
\hline horse & NR & NR & dog & serum & 0.00030 & died & Polley (1977) \\
\hline horse & $100^{\mathrm{b}}$ & tissue & $\operatorname{dog}(\times 2)$ & NR & NR & died, survived & Kaiser et al. (2010) \\
\hline horse & NR & NR & $\operatorname{dog}(\times 2)$ & serum & 0.0026 & died, survived & Polley (1977) \\
\hline horse & NR & NR & lion & liver & $1.14^{c}$ & died & Verster et al. (1990) \\
\hline horse & $23.0,0.6,4.5^{d}$ & tissue & Sumatran tiger $(\times 3)$ & serum & 0.022 & survived & Jurczynski and Zittlau (2007) \\
\hline lamb & NR & NR & dog & NR & NR & NR & VPIS \\
\hline pigeon & 400 & NR & cat & NR & NR & survived & VPIS \\
\hline dog & NR & NR & dog & NR & NR & survived & Fucci et al. (1986) \\
\hline sheep & NR & NR & dog & serum & 19.1 & survived & de Laforcade et al. (2001) \\
\hline sheep & NR & NR & dog & NR & NR & NR & VPIS \\
\hline whale & 321.5 & blubber & dog & urine & 0.004 & survived & Bischoff et al. (2011) \\
\hline
\end{tabular}

NR, not reported; VPIS, Veterinary Poisons Information Service (UK).

a. Reported in $\mathrm{mg} / \mathrm{mL}$.

b. Highest concentration detected.

c. Reported in $\mathrm{mg} / \mathrm{kg}$.

d. Three samples taken. 
Awareness within the veterinary sector-At present, veterinary curricula do not typically contain a mandatory environmental awareness component. Expanding veterinary training, along with public and practitioner outreach programs, could aid in the prevention of poisoning. Mechanisms in place, for example, forms trialed by US-based The Raptor Education Foundation, could be used by current and up-and-coming veterinarians to convey disposal information to owners during emotionally charged companion animal euthanasia situations. Anecdotally an array of reported perceptions and practices within the veterinary field were encountered during this research. These include the historical pentobarbital use for catching eagles and storks (Ciconiidae) by wildlife teams in Kenya and Zimbabwe and the routine feeding of contaminated meat to crocodiles (Crocodylinae).

\section{Conclusions}

This review was undertaken to consolidate and collate secondary pentobarbital poisoning incidents that have and continue to occur in wildlife and companion animals when freeranging or in captive settings, thereby providing greater insight into the extent of this issue. In total, 125 separate cases of poisoning, affecting 432 animals in the UK, US, Canada, South Africa, Germany, France, New Zealand, and Australia were collated. Of these, only 29 cases emanated from the published literature and the remaining 96 were acquired through database research, personal communications, and responses from a questionnaire sent to various veterinary surgical and wildlife rehabilitation centers, and zoos.

Individual incidents of companion animal poisonings (74/125 cases, $n=184$ ), primarily working dog breeds, tended to be most frequently reported, followed by wild animal poisonings $(43 / 125$ cases, $n=232$ ), primarily scavenging bird species, especially bald eagles. Of the animals poisoned in captivity ( 7 cases, $n=16)$, felids were reported to have been most affected. Albeit a small number of poisonings relative to the entire dataset, potential repercussions to captive breeding and reintroduction efforts were briefly discussed. Also considered were factors that could influence reporting rates, and therefore to inform general awareness of species vulnerability to secondary poisoning or extent of this issue, including: the proximal relationship between people and their pets (leading to rapid observation of debilitation and provision of treatment for companion animals), conspicuousness of and cultural affinity towards certain species, public aversion towards some of the affected species (e.g., as a nuisance or pest), and propensity of some species (e.g., avian scavengers) to disperse from a tainted carcass and succumb elsewhere, without being discovered.

An apparent reason for the occurrence of secondary pentobarbital poisoning is limited communication between relevant parties and organizations. In addition to local disposal regulations, the systems in place to prevent secondary pentobarbital poisoning include veterinary protocols, supplier facility inspection and product warning labels (DEFRA 2012, JAVMA 2003, Leary et al. 2013, Maslanka et al. 2013). Despite the addition of language warning of the potential repercussions (but only to wildlife) of residue exposure to pentobarbital-based products (e.g., by the FDAs Center for Veterinary Medicine) more than a decade ago, incidents of secondary poisoning continue to be reported to present day.

Awareness that exposure to pentobarbital can be harmful may fall under several categories of stakeholders. At one end of the spectrum are the veterinarians and certified animal caregivers that administer the drug to various types of animals, who also must be sufficiently informed of the secondary poisoning risks to ensure that carcasses are safely and securely disposed of. At the other end of the spectrum are those who receive pentobarbital-poisoned animals for supportive care or monitoring, which requires appropriate diagnosis and clinical response, or suitably comprehensive screening. In the middle are those tasked with managing euthanized animal carcasses, be it for feeding to captive wildlife (or, in some cases, companion animals) or for incorporation into pet food, and the wildlife agents and members of the public who encounter poisoned animals before care of the animals are initiated.

This review focused on veterinary practitioners and animal caregivers, but all relevant stakeholders must communicate with one another on this subject. Outreach to and by individuals who might be involved in responses to wildlife mortality events, for example game wardens, wildlife officers, veterinarians and marine mammal rescue and investigation organizations (such as the UK Cetacean Stranding Investigation Programme), law enforcement officers, pathologists and forensic scientists, is essential in resolving and preventing poisoning cases (Viner et al. 2016).

The disposal of euthanized animal carcasses remains firmly at the root of virtually all secondary pentobarbital poisoning cases. In theory, incorrect disposal of a carcass can lead to substantial fines and prison sentences for those responsible, including veterinarians. However, we caution that these penalties can deter individuals from reporting a poisoning incident, which leads to loss of valuable information.

Based on the information gathered during this review, we recommend follow-up in these areas:

1) continued development of standardized guidelines for euthanized animal carcass management and disposal

2) increased dissemination of information on the risks of pentobarbital poisoning to multiple stakeholders, with the promotion of information-sharing and interfacing between all stakeholders

3) increased caution towards carcasses for animal consumption, supported by standardized guidelines on safe sourcing and provision

4) individual scrutiny of regulations and safety standards currently in place around the rendering of euthanized animal carcasses and the incorporation of rendered byproducts into pet food products

5) separate review and investigation of pentobarbital (and other barbiturates) exposure and poisonings in pet food products

6) further investigation of any risks that other barbiturate and euthanasia drugs may have to companion animals, scavenging wildlife and captive carnivores

7) inclusion of pentobarbital (and, as applicable, other euthanasia drugs) in routine monitoring and opportunistic screening of all suspected poisoned animal cases 
Pentobarbital poisoning in wild, companion and captive carnivores is not a novel finding, nor is it likely to come as a surprise to those previously unaware of its existence who operate within the contaminant monitoring and wildlife forensics or enforcement realms. However, the fact that substantially more cases occur than are presently reported in the literature, that poisonings continue to present day, and the range of species that continue to be affected (some imperiled) should at the very least serve as a call for stronger preventive measures and better monitoring efforts to be implemented. In our view, a greater understanding and discussion surrounding secondary pentobarbital poisoning are overdue. We sincerely hope that colleagues will be compelled to explore this issue and the recommendations generated by the review process in further detail.

\section{Acknowledgments}

The primary author thanks Drs Andrew Butterworth and Ngaio Richards for their valuable guidance throughout the research period. Additionally, the Veterinary Poisons Information Service (VPIS), Veterinary Medicines Directorate (VMD), Royal Society for the Prevention of Cruelty to Animals (RSPCA), BirdLife International, Virginia Department of Game and Inland Fisheries (VDGIF), The National Wildlife Health Center (NWHC), The Wildlife Case Investigation Scheme operated by Science and Advice for Scottish Agriculture (SASA) in Scotland and Health and Safety Executive (HSE) in England, for the provision of comments and data for this research. The authors also would like to thank the respondents of the anonymous questionnaire for their contribution. We thank Carol Meteyer and Christina Davidson for their invaluable feedback on earlier versions of this manuscript.

\section{Disclosures}

This research did not receive any specific grant from funding agencies in the public, commercial, or not-for-profit sectors.

\section{References}

(AVMA) American Veterinary Medical Association. 2013. Guidelines for the euthanasia of animals: 2013 edition. Schaumburg, IL.

Anderson JF, Filkins D, Stowe CM, Arendt TD. 1976. Accidental relay toxicosis caused by pentobarbital euthanasia solution. J Am Vet Med Assoc. 175(6):583-4.

(AZA) Association of Zoos and Aquariums. 2016. Tiger (Panthera tigris) care manual, AZA, Silver Spring, MD.

(AZA) Association of Zoos and Aquariums. Year unknown. Cheetah species survival plan-husbandry manual. [Accessed 2017 May 26]. nagonline.net/676/ nutrition-chapter-cheetah-species-survival-plan-husbandry-manual

Barnett EA, Fletcher MR, Hunter K, Sharp EA. 2005. Pesticide poisoning of animals in 2004. DEFRA, London, United Kingdom.

Bauer H, Packer C, Funston PF, Henschel P, Nowell K. 2016. Panthera leo (errata version published in 2017). The IUCN Red List of threatened species. 2016:e.T15951A115130419. [Accessed 2018 Oct 7]. doi.org/10.2305/IUCN.UK. 2016-3.RLTS.T15951A107265605.en

BirdLife International. 2016a. Aquila chrysaetos. The IUCN Red List of threatened species. 2016:e.T22696060A93541662. [Accessed 2018 Oct 7]. doi.org/10.2305/ IUCN.UK.2016-3.RLTS.T22696060A93541662.en

BirdLife International. 2016b. Haliaeetus leucocephalus. The IUCN Red List of threatened species. 2016:e.T22695144A93492523. [Accessed 2018 Oct 7]. doi.org/ 10.2305/IUCN.UK.2016-3.RLTS.T22695144A93492523.en

BirdLife International. 2016c. Mycteria americana. The IUCN Red List of threatened species. 2016:e.T22697648A93627312. [Accessed 2018 Oct 7]. doi.org/ 10.2305/IUCN.UK.2016-3.RLTS.T22697648A93627312.en

BirdLife International. 2017a. Gyps fulvus (amended version of 2016 assessment). The IUCN Red List of threatened species. 2017:e.T22695219A118593677.
[Accessed 2018 Oct 7]. doi.org/10.2305/IUCN.UK. 2017-3.RLTS.T22695219A118593677.en

BirdLife International. 2017b. Milvus milvus (amended version of 2016 assessment). The IUCN Red List of threatened species. 2017:e.T22695072A110921280. [Accessed 2018 Oct 7]. doi.org/10.2305 IUCN.UK.2017-1.RLTS.T22695072A110921280.en

BirdLife International. 2018. Corvus brachyrhynchos. The IUCN Red List of threatened species. 2018:e.T22705990A131945410. [Accessed Nov. 21, 2018]. doi.org/10.2305/IUCN.UK.2018-2.RLTS.T22705990A131945410.en

Bischoff K, Jaeger R, Ebel JG. 2011. An unusual case of relay pentobarbital poisoning in a dog. J Med Toxicol. 7:236-9.

Boshoff A, Botha A, Kruger S, Rushman I, Wolter K. 2011. The SASOL guide to the establishment and operation of supplementary feeding sites for vultures. Endangered Wildlife Trust, Modderfontein.

Brakes CR, Smith RH. 2005. Exposure of non-target small mammals to rodenticides: short-term effects, recovery and implications for secondary poisoning. J Appl Ecol. 42(1):118-28.

Brauer C, Tipold A, Desel H, Stein VM. 2009. Barbiturate intoxication in two dogs confirmed by toxicological urinalysis. J Small Anim Pract. 50(8):423-5.

Campbell VL, Butler AL, Lunn KF. 2009. Use of a point-of-care urine drug test in a dog to assist in diagnosing barbiturate toxicosis secondary to ingestion of a euthanized carcass. J Vet Emerg Crit Care (San Antonio). 19(3):286-291.

Ciamillo S, Peck G, Williams M, Splan RK, Shea Porr CA. 2014. Impact of composting on drug residues in large animal mortality. Virginia Cooperative Extension, publication APSC-59P.

Corona M. 2015. Euthanized horse blamed for contaminated meat. [Accessed 2018 Nov 22]. rgj.com/story/news/2015/03/12/animal-ark-toxicology-results-showsbarbiturates-in-meat/70194788

de Laforcade AM, Rozanski E, Good L, Rush JE. 2001. Mechanical ventilation of a dog with pentobarbital intoxication. J Vet Emerg Crit Care. 11(1):33-7.

(DEFRA) Department for Environment, Food and Rural Affairs. 2012. Fallen stock and safe disposal of dead animals. [Accessed 2017 June 28]. gov.uk/ guidance/fallen-stock

Dubie TR, Talley JL, Wayadande AW, Payne JB, Dillwith J. 2017. Filth fly activity associated with composted and non-composted beef cadavers and the effect of composting on volatile organic compounds. J Med Entomol. 54(5):1299-1304.

Durant S, Mitchell N, Ipavec A, Groom R. 2015. Acinonyx jubatus. The IUCN Red List of threatened species. 2015:e.T219A50649567. [Accessed 2018 Oct 7]. doi.org/10.2305/IUCN.UK.2015-4.RLTS.T219A50649567.en

Edgson FA, Payne JM. 1967. The dangers of poisoning domestic pets with meat from animals subjected to barbiturate euthanasia. Vet Rec. 80(11):364

Elliot KH, Duffe J, Lee SL, Mineau P, Elliott JE. 2006. Foraging ecology of bald eagles at an urban landfill. Wilson J Ornithol. 118(3)380-90.

Emke E, Helmus R, de Voogt P. 2011. Trace analysis of barbiturates in wastewater by HPLC-LTQ-Orbitrap MS. SETAC Europe 21 st annual meeting abstract book; 2011 May 15-19.

Entis P. 2019. JBS knowingly distributed products containing euthanasia drug [Accessed 2019 Sept 18]. foodsafetynews.com/2019/05/ibs-knowinglydistributed-pentobarbital-adulterated-products-to-customers

(FDA) US Food and Drug Administration. 2017. Party Animal recalls dog food due to potential presence of pentobarbital. [Accessed 2017 May 25]. fda.gov/safety/ recalls-market-withdrawals-safety-alerts/party-animal-recalls-dog-food-duepotential-presence-pentobarbital

Fucci V, Monroe WE, Riedesel DH, Jackson LL. 1986. Oral pentobarbital intoxication in a bitch. J Am Vet Med Assoc. 188(2):191-2.

Gese EM, Bekoff M, Andelt W, Carbyn L, Knowlton F. 2008. Canis latrans. The IUCN Red List of threatened species. 2008:e.T3745A10056342. [Accessed 2018 Oct 7]. doi.org/10.2305/IUCN.UK.2008.RLTS.T3745A10056342.en

Gonzales B, Clifford D. 2015. Dear veterinary college. Department of Fish and Wildlife, Sacramento, California.

Goodrich J, Lynam A, Miquelle D, Wibisono H, Kawanishi K, Pattanavibool A, Htun S, Tempa T, Karki JJ, Jhala Y, Karanth U. 2015. Panthera tigris. The IUCN Red List of threatened species. 2015:e.T15955A50659951. [Accessed 2018 Nov 21]. doi.org/10.2305/IUCN.UK.2015-2.RLTS.T15955A50659951.en

Guitart R, Sachana M, Caloni F, Croubels S, Vandenbroucke V, Berny P. 2010. Animal poisoning in Europe: part 3: wildlife. Vet J. 183(3):260-5.

Hertel F. 1994. Diversity in body size and feeding morphology within past and present vulture assemblages. Ecology. 75(4):1074-84.

Hewitt S, Williamson S, Woodger N, Streete P, Cracknell J, Lewis J. 2010. Secobarbital poisoning in an Amur tiger (Panthera tigris altaica). Vet Rec. 167(5): $178-80$.

Hoffmann M, Sillero-Zubiri C. 2016. Vulpes vulpes. The IUCN Red List of threatened species. 2016:e.T23062A46190249. [Accessed 2018 Oct 7]. iucnredlist.org/species/23062/46190249

Humphreys DJ, Longstaffe JA, Stodulski BJ, Fysh RR, Lopatkin I. 1980. Barbiturate poisoning from pet shop meat: Possible association with perivascular injection. Vet Rec. 107:517.

(IWC) International Whaling Commission. 2015. Report of the IWC workshop on euthanasia protocols to optimize welfare concerns for stranded cetaceans. [Accessed 2019 April 25]. ascobans.org/en/document/report-iwc-workshopeuthanasia-protocols-optimize-welfare-concerns-stranded-cetaceans 
(JAVMA) Journal of the American Veterinary Medical Association. 2003. Warning added to euthanasia products. [Accessed 2017 Aug 31]. avma.org/News/ IAVMANews/Pages/030915r.aspx

Jiang Z, Li C, Fang H, Meng Z, Yan Z. 2007. Captive-bred tigers and the fate of wild tigers. BioScience. 57(9):725.

Jozwiak L. 2009. Secondary poisoning to bald eagles from pentobarbital. Refuge Notebook. 11(41):79-80.

Jurczynski K, Zittlau E. 2007. Pentobarbital poisoning in Sumatran tigers (Panthera tigris sumatrae). J Zoo Wildl Med. 38(4):583-4.

Kaiser AM, McFarland W, Simeon RS, Reisebuch MF. 2010. Secondary pentobarbital poisoning in two dogs: a cautionary tale. J Vet Diagn Investig. 22:632-4.

König C. 1983. Interspecific and intraspecific competition for food among Old World vultures. In: Wilbur SR, Jackson JA, editors. Biology of Old World Vultures. Berkeley: University of California Press, CA. p. 153-71.

Krueger BW, Krueger KA. 2002. Secondary pentobarbital poisoning of wildlife. USFWS, Stafford, VA.

Langelier KM. 1993. Barbiturate poisoning in twenty-nine bald eagles. In: Redig PT, Cooper J, Remple JD, Hunter DB, editors. Raptor Biomedicine. University of Minnesota Press, MN. p 231-2.

Leary S, Underwood W, Anthony R, Cartner S, Corey D, Grandin T et al. 2013. Disposal of animal remains. In: AVMA Guidelines for the Euthanasia of Animals: 2013 edition. American Veterinary Medical Association. p. 16-7.

Lehner PN. 1976. Coyote behavior: implications for management. Wildl Soc Bull. 4(3):120-6.

Linkie M, Wibisono HT, Martyr DJ, Sunarto S. 2008. Panthera tigris ssp. sumatrae. The IUCN Red List of threatened species. 2008: e.T15966A5334836. [Accessed 2017 May 26]. doi.org/10.2305/IUCN.UK.2008.RLTS.T15966A5334836.en

Martin HD, Mallock A. 1987. Management of barbiturate intoxication in cougars (Felis concolor). J Zoo Animal Med. 18(2/3):100-3.

Maslanka M, Ward A, Moore DE. 2013. A field guide to AZA accreditation from a nutrition perspective. AZA, Silver Spring, MD.

Mech LD, Boitani L (IUCN SSC wolf specialist group). 2010. Canis lupus. The IUCN Red List of threatened species. 2010:e.T3746A10049204. [Accessed 2018 Oct 7]. doi.org/10.2305/IUCN.UK.2010-4.RLTS.T3746A10049204.en

Miquelle D, Darman Y, Seryodkin I. 2011. Panthera tigris ssp. altaica. The IUCN Red List of threatened species. 2011: e.T15956A5333650. [Accessed 2017 May 26]. doi.org/10.2305/IUCN.UK.2011-2.RLTS.T15956A5333650.en

Neal DJ. 2018. Dog food 'withdrawn' over euthanasia drug concerns. Chicago Times. [Accessed 2018 Nov 23]. chicagotribune.com/business/ct-biz-dog-food-recallgravy-train-ol-roy-pentobarbital-20180220-story.html

Nielsen C, Thompson D, Kelly M, Lopez-Gonzalez CA. 2015. Puma concolor (errata version published in 2016). The IUCN Red List of threatened species. 2015:e.T18868A97216466. [Accessed 2018 Oct 7]. doi.org/10.2305/IUCN.UK. 2015-4.RLTS.T18868A50663436.en

(NAG) Nutrition Advisory Group, Association of Zoos and Aquariums. Year unknown. Feeding of vertebrate animal carcass and whole body prey statement. [Accessed 2017 May 23]. nagonline.net/guidelines-aza-institutions/nag-carcassfeeding-statement

O'Rourke K. 2002. Euthanized animals can poison wildlife: veterinarians receive fines. [Accessed 2017 Feb 8]. avma.org/News/JAVMANews/Pages/s011502d.aspx

Payne J, Farris R, Parker G. 2012. Quantification of sodium pentobarbital residues from equine mortality compost piles. Proceedings of an International Symposium: Managing Animal Mortalities, Products, By-products and Associated Health Risk Connecting Research, Regulations and Response; 2012 May 21-24; Dearborn, Michigan.

Peschka M, Eubeler JP, Knepper TP. 2006. Occurrence and fate of barbiturates in the aquatic environment. Environ Sci Technol. 40(23):7200-6.

Pinasseau M. 2015. Les intoxications des rapaces dues aux activités humaines en France [doctorate's thesis], University of Toulouse.
Polley L, Weaver BM. 1977. Accidental poisoning of the ox by barbiturates in meat Vet Rec. 100(3):48.

(RCVS) Royal College of Veterinary Surgeons. 2012a. Euthanasia of animals. [Accessed 2017 June 26]. rcvs.org.uk/advice-and-guidance/code-of-professionalconduct-for-veterinary-surgeons/supporting-guidance/euthanasia-of-animals

(RCVS) Royal College of Veterinary Surgeons. 2012b. Miscellaneous procedures: legal and ethical considerations. [Accessed 2017 June 26]. rcvs.org.uk/advice-andguidance/code-of-professional-conduct-for-veterinary-surgeons/supportingguidance/miscellaneous

Reid TC. 1978. Barbiturate poisoning in dogs. N Z Vet J. 26(7):190.

Richards N, Gilbert M, Taggart M, Naidoo V. 2017. A cautionary tale: diclofenac and its profound impact on vultures. In: Dellasala DA, Goldstein MI, editors Encyclopedia of the Anthropocene. Vol 5. Oxford: Elsevier, UK; 2018. p. 247-55.

(RSPB) Royal Society for the Protection of Birds. Year unknown a. Illegal killing of birds of prey in Scotland, 1994-2014: a review. RSPB, Edinburgh.

(RSPB) Royal Society for the Protection of Birds. Year unknown b. Northern Ireland red kites. [Accessed 2017 June 25]. rspb.org.uk/our-work/conservation/ projects/northern-ireland-red-kites

Russell RE, Franson JC. 2014. Causes of mortality in eagles submitted to The National Wildlife Health Center, 1975-2013. Wildl Soc Bull. 38(4):697-704.

Sanchez-Barbudo IS, Caramello PR, Mateo R. 2012. Intentional and accidental poisoning of wild and domestic animals in Spain: differences between the regions. Crit Rev Toxicol. 29:20-8.

Shearer JK, Griffin D, Cotton SE. 2018. Humane euthanasia and carcass disposal. Vet Clin North Am Food Anim Pract. 34(2):355-74.

Shore RF, Taggart MA, Smits J, Mateo R, Richards N, Fryday S. 2014. Detection and drivers of exposure and effects of pharmaceuticals in higher vertebrates. Philos Trans Royal Soc B. 369.

Shultz S, Baral HS, Charman S, Cunningham AA, Das D, Ghalsasi GR, et al. 2004. Diclofenac poisoning is widespread in declining vulture populations across the Indian subcontinent. Proc R Soc Lond [Biol]. 271(6)458-60.

Stetler S. 2011. Food safety and sanitation. Kansas City, Missouri, USA

Taggart MA, Richards N, Kinney CA. 2015. Impacts of pharmaceuticals on terrestrial wildlife. In: Hester RE, Harrison RM, editors. Pharmaceuticals in the Environment. p. 216-54.

Thomas N. 1999. Barbiturates. In: Friend M, Franson JC, editors. Field Manual of Wildlife Diseases. USGS. p. 349-50.

Verster A, Schroder HHE, Nestbit JW. 1990. Accidental pentobarbital poisoning in a lioness. J S Afri Vet Assoc. 61(1):37-8.

Viner TC, Hamlin BC, McClure PJ, Yates BC. 2016. Integrating the forensic sciences in wildlife case investigations. Vet Pathol. 53(5):1103-6.

Williams JH, Bester L, Venter L, Pretorius D, Greyling F. 2011. Barbiturate ingestion in three adult captive tigers (Panthera tigris) and concomitant fatal botulism in one. J S Afri Vet Assoc. 82(4):244-9.

Williamson GT. 1970. An unusual poisoning of dogs. Aust Vet J. 47:71.

Zorrilla I, Martinez R, Taggart MA, Richards N. 2014. Suspected flunixin poisoning of a wild Eurasian Griffon vulture from Spain. Conserv Biol. 29(2):58792.

Zorrilla I, Richards NL, Benítez JR, Calvino M, Fernandez I, Rodriguez F. 2018. Case study: detection of two nonsteroidal anti-inflammatory drugs (NSAIDs) in the eggs of captive-reared bearded vultures at a breeding center in southern Spain $J$ Wildl Reh. 38(1):15-27.

\section{Supporting Information}

Additional supporting information may be found online in the supporting information section at the end of the article: 